\title{
DERIVATIVE MARKETS-USING OPTIONS TRADING STRATEGY IN MONGOLIAN STOCK MARKET
}

\author{
Davaadalai Darkhabaatar \\ Student of Master of Finance, Shanghai University
}

Article DOI: $\underline{\text { https://doi.org/10.36713/epra6544 }}$

\begin{abstract}
This study identifies some opportunities to introduce derivative instruments based on the practical experience of other countries, and provides some estimates of the implementation of derivative market mechanisms, pricing, and trading strategies. KEY WORDS: Financial derivative, option, and spread
\end{abstract}

\section{INTRODUCTION}

Nowadays, many countries have been using stock market in order to stabilize economic situation and provide continuous progress of economic. Thus, stock market is one of the important factors which can improve and motivate financial market and also it is important for development of macroeconomics. Therefore, stock market is crucial for emerging countries economic, such as Mongolia.

There was a tendency that researchers tought that national economic growth is related to the development of banking sector. However, this trend has been changing to the new concept which economic progress is related to the development of stock market in last ten years. For example, some empiric studies written by Demirguc Kunt and Levine (1996), Sing (1997), and Zervos (1998) has proved that securities market is really important for long term stable growth of national economic.

\section{The purpose of the study}

Our goal is that study about opportunities which can lead to increase return and reduce risk in Mongolian stock market using derivative instruments. According to the purpose, we suggest following intention:

- Define optimal portfolio strategy based on features of each stocks,

- Find future's strategy on the basis of forecasting stock value,

- Estimate expected return of stock market affected by derivative instruments.

\section{LITERATURE REVIEW}

A great deal of effort has been expanding in investigating the important influence of the development of the derivatives market on various aspects of financial systems. Haiss and Sammer (2010) explore the role of derivatives in the nexus between finance and growth via three channels: volume, efficiency, and risk. First, in the volume channel, the development of derivatives markets influences the financial market and economic growth by facilitating and increasing the accumulation of capital. It enhances the allocation of resources into investment activities at higher rates of return with the help of the mobility of savings and the higher potential of investment in an enormous range of risky projects. Second, the efficiency channel is a summary of several functions, such as an efficient substitute for cash market trade, resource movement across time and space, and an information provider for risk management and price strategy. It is therefore beneficial for such agents as firms, financial institutions, and the government to have a larger combination of funding sources at lower costs. Third, the risk channel is concerned with the negative impact 
of derivatives market development on the financial market and economic growth. It may raise speculation about underlying assets, making the financial markets more volatile and adding more uncertainty to the economy. However, using derivatives as hedging instruments could be beneficial for firms and agents (see e.g., Allayannis and Ofek 2001; Bartram et al. 2009; Hammoudeh and McAleer 2013; Huang et al. 2017; Tanha and Dempsey 2017).

Sendeniz-Yüncü et al. (2018) mention that a well-functioning derivatives market makes it possible for firms to share risks efficiently and allows them to conduct projects with higher risk and consequently to boost economic growth. At the same time, agents, such as investors, consumers, and producers, can rely on the derivatives market as an information channel that reflects equilibrium prices so that they can make the right decisions, fostering the efficiency of resource distribution and consequently resulting in economic growth.

The causal relation between the futures market and economic growth in both developed and developing countries is highlighted in Sendeniz-Yüncü et al. (2018)'s study based on time-series data. They find that, in 29 out of the 32 countries studied, the two variables of concern have a long-run relationship and that middle-income countries have a Granger-causality effect from the futures market to economic growth while in high-income countries the effect is reversed. These authors distinguish these opposite unidirectional causations between futures market development and economic growth. On the one hand, the direction starts with futures market development to economic growth in most countries with relatively low real GDP per capita. On the other hand, in countries with a relatively high real per capita GDP, economic growth tends to lead to the development of a futures market. Like Khan et al. (2017) using a panel vector autoregressive method and the Granger causality approach, Vo et al. (2019) show the existence of bidirectional Granger causality between the derivatives market and economic growth, although the causal relation differs between high- and middle-income countries.

The empirical studies focus on the links between economic growth and financial market development, rather than the derivatives market. Various research has approached economic growth via the development of financial intermediaries, such as banking sector development (Beck et al. 2000; King and Levine 1993; Levine et al. 2000; Levine 2005; Menyah et al. 2014; Pradhan et al. 2014; Chaiechi 2012), stock market development (Tsouma 2009; Ang and McKibbin 2007; Huang et al. 2000), and bond market development (Cos kun et al. 2017; Thumrongvit et al. 2013). ${ }^{1}$ Pradhan et al. (2014) conduct an analysis on paired relations among four economic componentsincluding the banking sector, stocks, and economic growth - and macro variables, such as foreign direct investment (FDI), trade openness, inflation rate, and government consumption and expenditure. Of these selected variables, the financial

\section{OVERVIEW OF THE DERIVATIVE MARKET}

Derivative market has not been developed well in Mongolia. However, Mongolian central bank has been using swap contract in order to reduce exchange risk in recent years. Also, most of the petrol companies has also been using derivative instruments for buying petrol from global market.

\section{Financial Derivatives}

Financial derivatives have been widely used to prevent risk in resent years. For instance, total GDP of the world was 84,835.46 billion USD in 2018 and market value of derivative market was 544,000 billion USD in 2018. ${ }^{1}$ It shows that securities market, especially derivatives market, can define development of modern financial market. Derivatives market can lead to huge amount of loss because of misleading valuation even though it is good method to hedging financial risk. We can see it from financial crisis of USA in 2018 because of mortgage market and example of Baring bank. A derivative is a financial instrument that derives its performance from the performance of an underlying asset.

\section{Forward}

Forward commitments are contracts entered into at one point in time that require both parties to engage in a transaction at a later point in time (the expiration) on terms agreed upon at the start. The parties establish the identity and quantity of the underlying, the manner in which the contract will be executed or settled when it expires, and the fixed price at which the underlying will be exchanged. This fixed price is called the forward price. ${ }^{2}$

\footnotetext{
${ }^{1}$ Statistical release: OTC Derivatives statistic at end June - 2019 By BANK OF INTERNATIONAL SETTLEMENTS

${ }^{2}$ CFA curriculum level 1 book 6 Derivatives and alternative investments
} 
A forward contract is an over-the-counter derivative contract in which two parties agree that one party, the buyer, will purchase an underlying asset from the other party, the seller, at a later date at a fixed price they agree on when the contract is signed.

$F_{0}(T)=S_{0}\left(1+R_{f}\right)^{T}(1)$

Where:

$S_{0}-$ Spot price at $t=0$

$R_{f}$ - risk free rate

T-Time to maturity (2)

$\mathrm{V}_{\mathrm{t}}(\mathrm{T})=\mathrm{S}_{\mathrm{t}}-\mathrm{F}_{0}(\mathrm{~T}) /(1+\mathrm{Rf})^{\mathrm{T}-\mathrm{t}}$

At expiration, the payoff to a long forward is $S_{T}-F_{0}(T)$, the difference between the spot price of price of the asset at expiration and the price of the forward contract.

Figure 1. Payoffs from forward contract
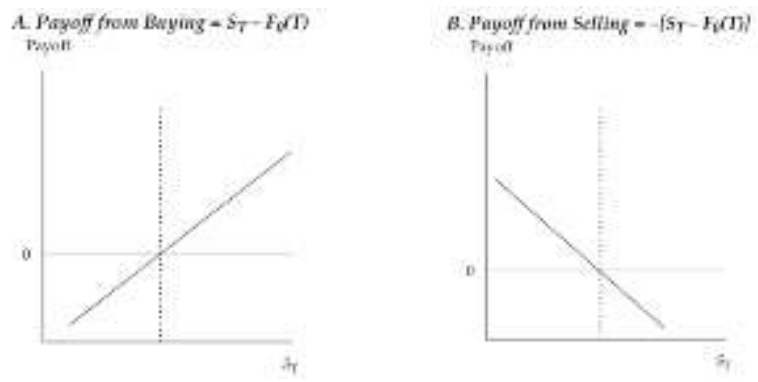

\section{Futures}

A futures contract is a standardized derivative contract created and traded on a futures exchange in which two parties agree that one party, the buyer, will purchase an underlying asset from the other party, the seller, at a later date and at a price agreed on by the two parties when the contract is initiated and in which there is a daily settling of gains and losses and a credit guarantee by the futures exchange through its clearinghouse.

\section{Options}

Options are traded both on exchanges and in the over-the-counter market. There are two types of option. A call option gives the holder the right to buy the underlying asset by a certain date for a certain price. A put option gives the holder the right to sell the underlying asset by a certain date for a certain price. The price in the contract is known as the exercise price or strike price; the date in the contract is known as the expiration date or maturity. American options can be exercised at any time up to the expiration date. European options can be exercised only on the expiration date itself. ${ }^{3}$

\footnotetext{
${ }^{3}$ John C Hull - Options, Futures, and other derivatives
} 
$C_{T}=\operatorname{Max}\left(0, S_{T}-X\right)-$ Payoff to the call buyer (3)

$\Pi=\operatorname{Max}\left(0, S_{T}-X\right)-C_{0}$ (profit to the call buyer), (4)

To the seller, who received the premium at the start, the payoff is

$-C_{T}=-\operatorname{Max}\left(0, S_{T}-X\right)$ (payoff to the call seller),(5)

The profit is

$\Pi=-\operatorname{Max}\left(0, S_{T}-X\right)+C_{0}$ (profit to the call seller),(6)

Figure 2. Payoff and Profit from a call option
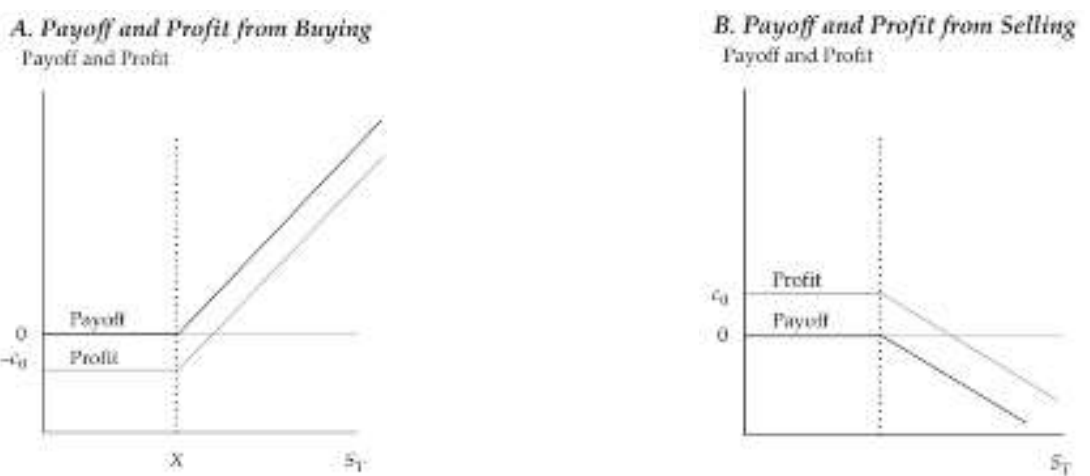

Figure 3. Payoff and profit from a Put option
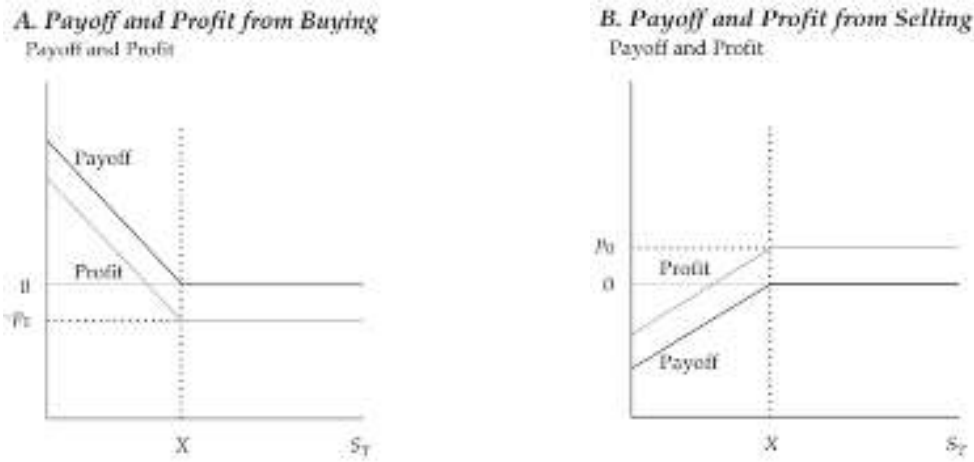

Figure 4. Arbitrage, Replication, and Derivatives

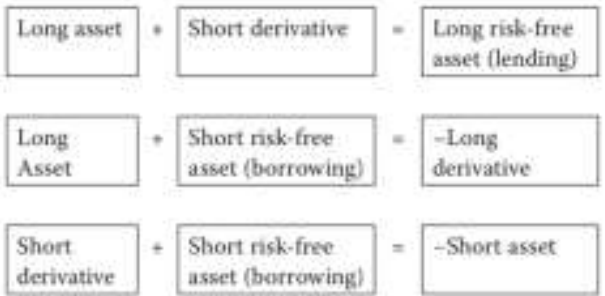

Understanding the features of the four basic types of vertical spreads - bull call, bear call, bull put, and bear put - is a great way to further learning about relatively advanced option strategies. 
Options spreads are common strategies used to minimize risk or bet on various market outcomes using two or more options. In a vertical spread, an individual simultaneously purchases one option and sells another at a higher strike price using both calls or both puts. A bull vertical spread profits when the underlying price rises; a bear vertical spread when it falls.

A bull call spread is purchasing a call option, and simultaneously selling another call option (on the same underlying asset) with the same expiration date but a higher strike price. Since this is a debit spread, the maximum loss is restricted to the net premium paid for the position, while the maximum profit is equal to the difference in the strike prices of the calls less the net premium paid to put on the position.

Figure 5. Bull and bear call spread
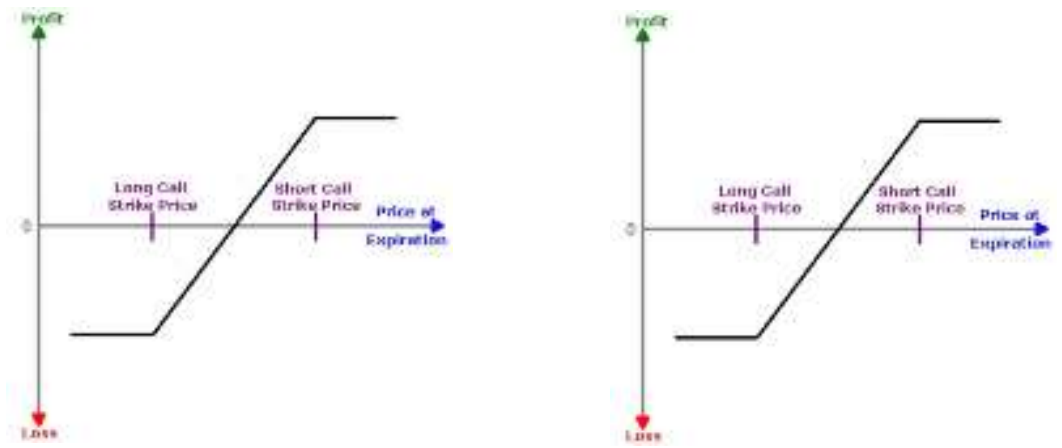

A bear call spread is selling a call option, and simultaneously purchasing another call option with the same expiration date but at a higher strike price. Since this is a credit spread, the maximum gain is restricted to the net premium received for the position, while the maximum loss is equal to the difference in the strike prices of the calls less the net premium received.

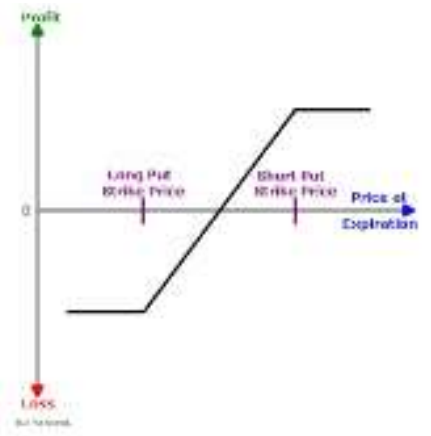

Figure 6. Bull and bear put spread

A bull put spread is writing a put option, and simultaneously purchasing another put option with the same expiration date but a lower strike price. Since this is a credit spread, the maximum gain is restricted to the net premium received for the position, while the maximum loss is equal to the difference in the strike prices of the puts less the net premium received.

A bear put spread is purchasing a put option, and simultaneously selling another put option with the same expiration date but a lower strike price. Since this is a debit spread, the maximum loss is restricted to the net premium paid for the position, while the maximum profit is equal to the difference in the strike prices of the puts less the net premium paid to put on the position. ${ }^{4}$

\section{Swap}

A swap is an over-the-counter derivative contract in which two parties agree to exchange a series of cash flows whereby one party pays a variable series that will be determined by an underlying asset or rate and the other party pays either (1) a variable series determined by a different underlying asset or rate or (2) a fixed series. Swaps

\footnotetext{
${ }^{4}$ www.investpedia.com
} 
are relatively young financial instruments, having been created only in the early 1980s. Thus, it may be somewhat surprising to learn that the swap is the most widely used derivative, a likely result of its simplicity and embracement by the corporate world. The most common swap is the fixed-for-floating interest rate swap. In fact, this type of swap is so common that it is often called a "plain vanilla swap" or just a "vanilla swap," owing to the notion that vanilla ice cream is considered plain (albeit tasty) 5 .

\section{Figure 7. Convert a floating rate loan to a fixed rate loan}

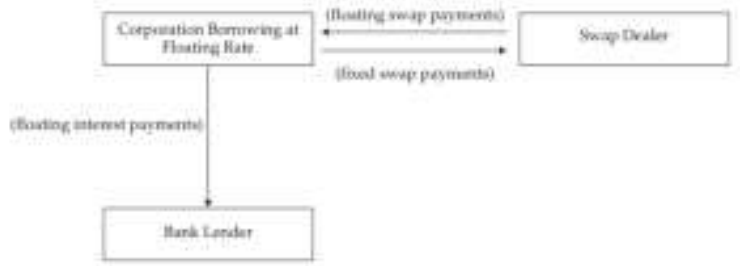

\section{RESEARCH METHODOLOGY}

We address general trend of capital market of Mongolia and, then determine what factors are affecting for stock price. In order to do that, we will make time-series analysis for most activily traded stocks, TOP-20 index.

Moreover, we will choose one stock which is traded in Mongolian stock market (MSE) and make following steps in order to do analysis:

1. Define seasonal effect and shock of business cycle

2. Forecast future stock price using statistical models named autoregressive conditional heteroskedasticity (ARCH) and generalized ARCH (GARCH).

3. Estimate cost of call and put options in different time frame using Black Scholes model based on historical data of the stock.

4. Determine option strategy to use in the stock based on forecast of price and cost estimation of option. We made analysis based on data between 2006 and 2019.

\section{ARCH Model}

When examining a single time series, such as AR model, autoregressive conditional heteroskedasticity (ARCH) exists if the variance of the residuals in one period is dependent on the variance of the residuals in a previous period. When this condition exists, the standard errors of the regression coefficient in AR models and the hypothesis tests of these coefficients are invalid. The ARCH regression model is expressed as:

$$
\widehat{\varepsilon_{t}^{2}}=a_{0}+a_{1} \widehat{\varepsilon_{t-1}^{2}}+\mu_{t}(7)
$$

Where $a_{0}$ is the constant $\mu_{t}$ is an error term.

AR Model

If the coefficient, $a_{1}$, is statistically different from zero, the time series is ARCH.

When the dependent variable is regressed against one or more lagged values of itself, the resultant model is called as an autoregressive model (AR) ${ }^{6}$.

$$
X_{t}=b_{o}+b_{1} X_{t-1}+\varepsilon_{t}(8)
$$

\section{EMPIRICAL RESULTS}

TOP-20 index includes stocks information of Mongolian biggest 20 public companies. Therefore, we calculated monthly effect of TOP-20 index in order to see monthly trend of MSE.

\footnotetext{
${ }^{5}$ CFA curriculum level 1 book 6 Derivatives and alternative investments

${ }^{6}$ CFA Schweser Notes Level 2 book 1
} 
Figure 8. Monthly effect of TOP-20 index

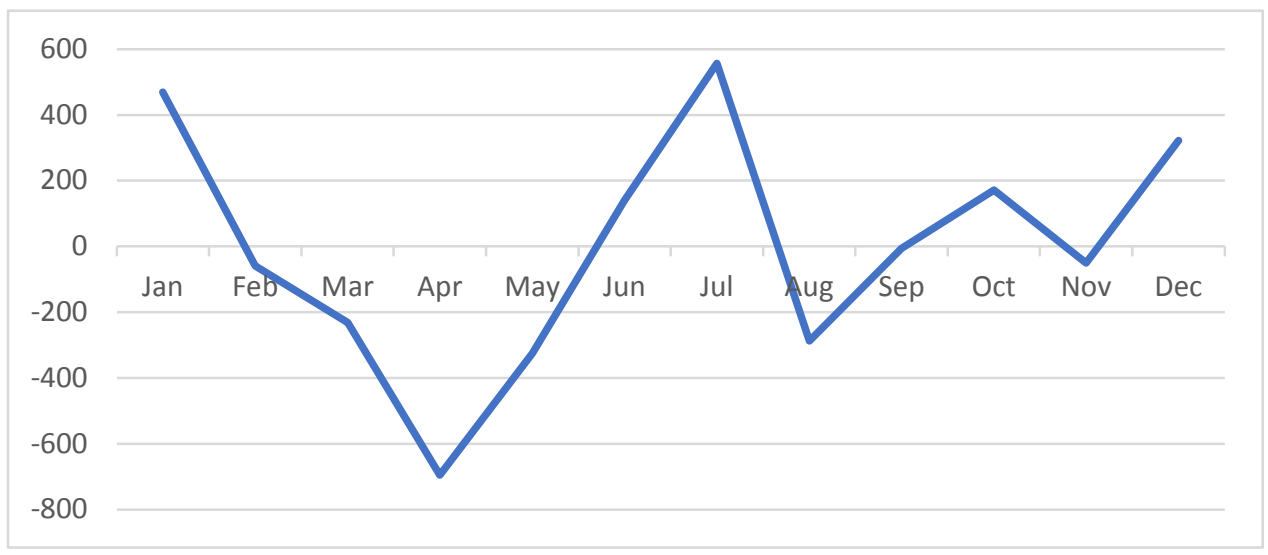

We can see from the figure 8 that Mongolian stocks tend to decrease early of the year and increase late of the year.

Figure 9 Shock effect of TOP-20 index

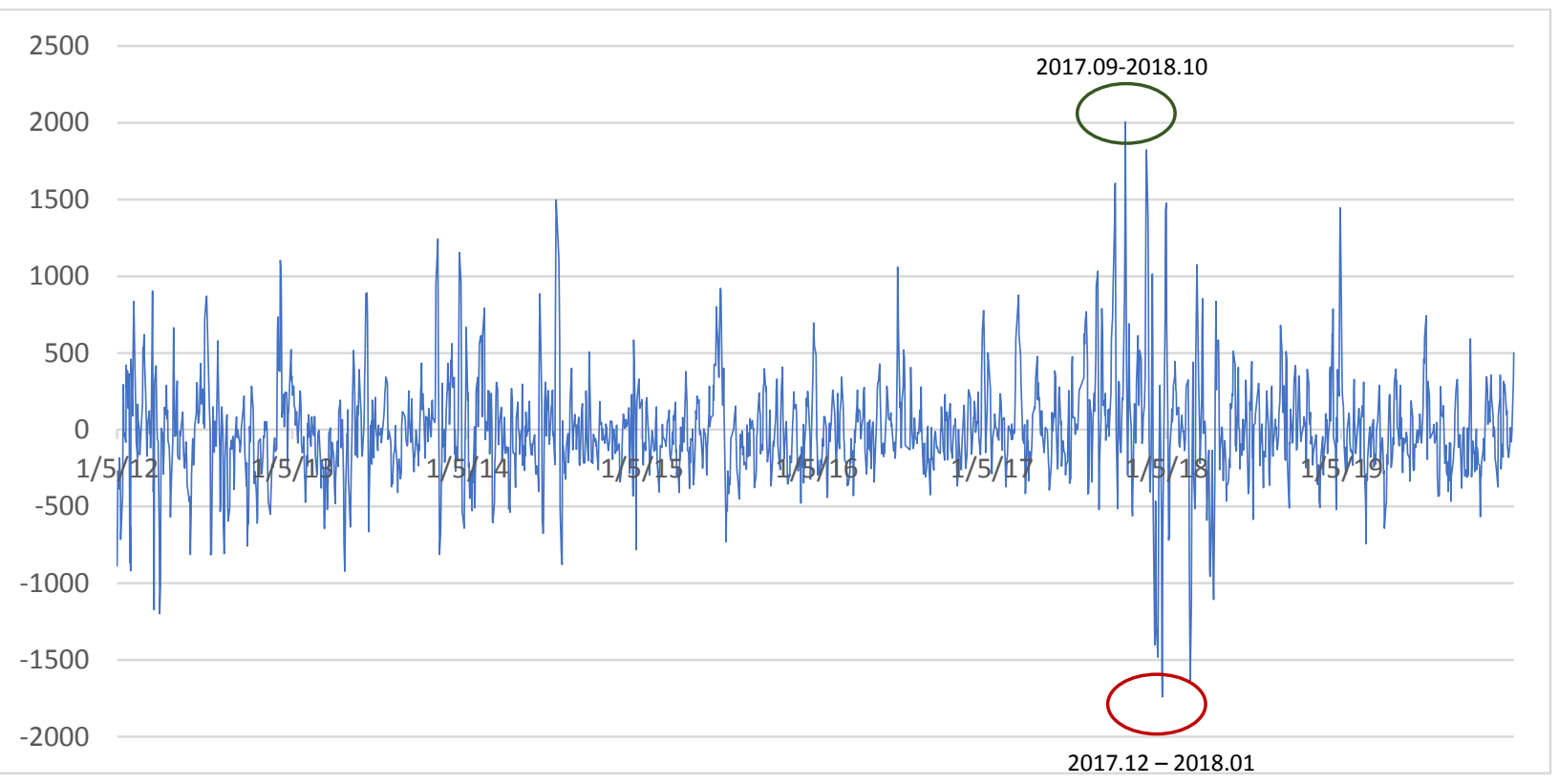

The biggest negative effect is in January of every year, and biggest positive effect is September and October of every year between 2012 and 2019. The strongest effect of 2017 and 2019 is related to the activation of foreign investors.

In order to reduce investment risk, portfolio is basic and efficient method and we chose two following biggest companies which operates in different industry because we thought those companies has low risk compared to others.

- $\quad$ APU JSC (APU) 
- $\quad \mathrm{KHUH}$ GAN (HGN)

\section{APU JSC}

Established in 1924, APU JSC has operated with vodka, spirit, beer, water and soft drinks production plants. During the first half of 2018, the company has employed 703 persons and produced 41.5 million L of beverage.

Figure 10. Historical stock closing price of APU /MNT/

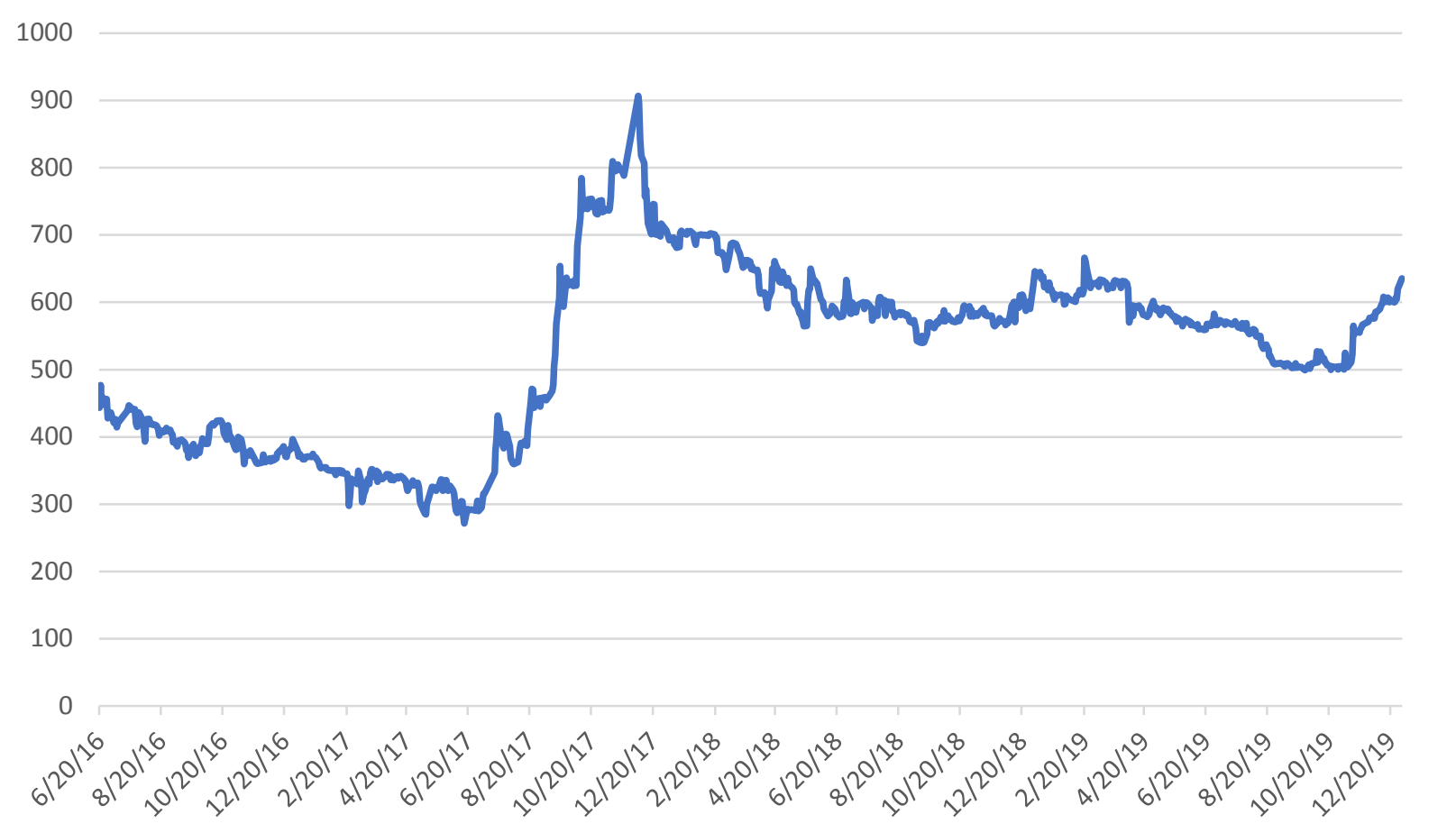

APU JSC has split (10 times 1 per share was 3700 MNT before split) stock price in June of 2016. After that stock price has increased to reach peak point 906.8 MNT for per share on December of 2017. At this time the company has merged with a domestic beverage company named Spirt bal buram. 


\section{Figure 11. Return volatilty of APU JSC}

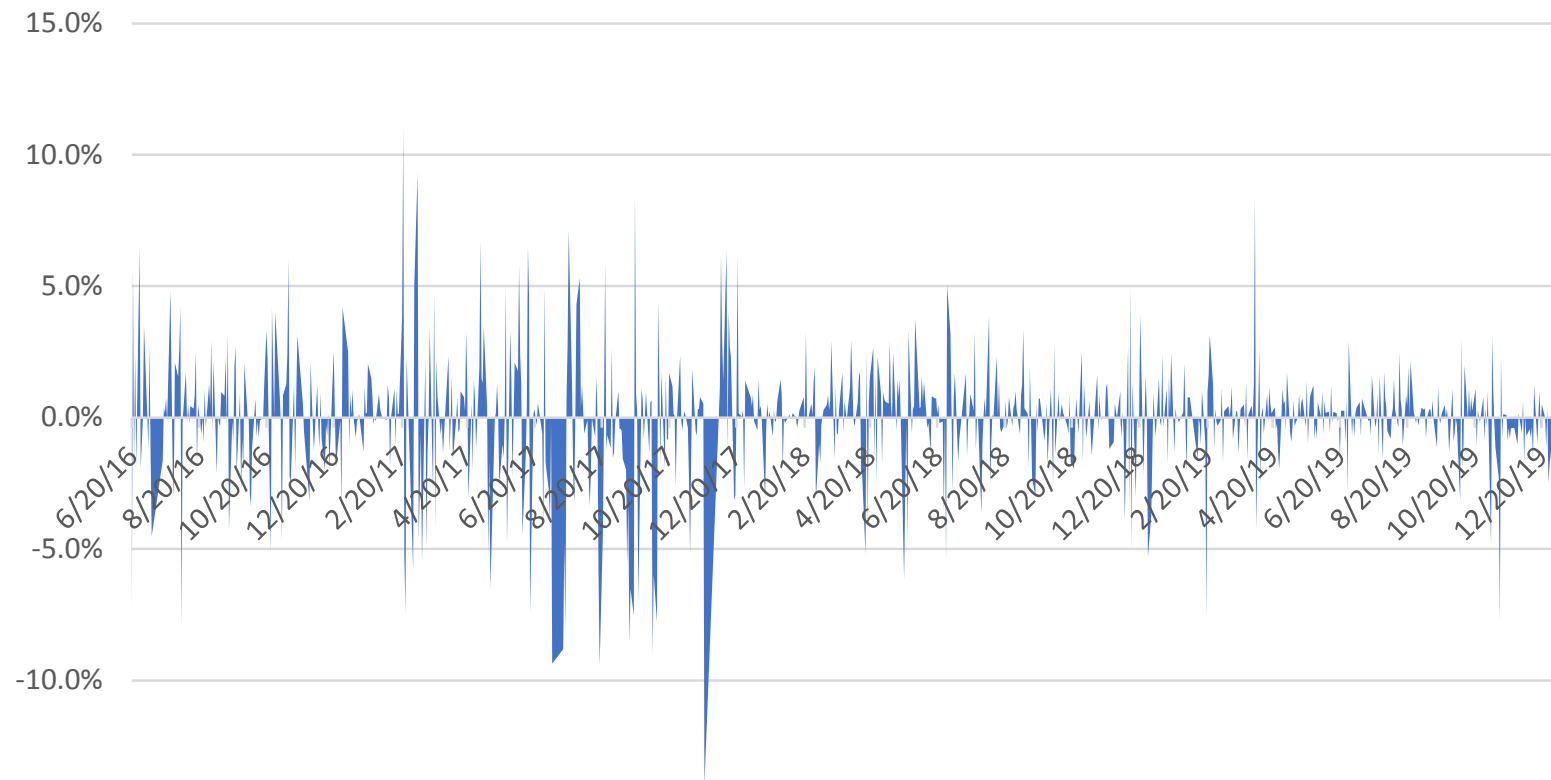

We can see that volatility was very high from 2017 to 2018. Standard division of return was $2.31 \%$ and average was $0.04 \%$ over the period. equation is:

In the following section, we will study hedging opportunities of risk using Black Scholes equation. General

\section{Value of call option}

$$
\mathrm{C}=S_{0} N\left(d_{1}\right)-K e^{-r T} N\left(d_{2}\right)
$$

\section{Value of put option}

$$
\mathrm{P}=\mathrm{K} e^{-r T} N\left(-d_{2}\right)-S_{0} N\left(-d_{1}\right)
$$

Where:

$$
d_{1}=\frac{\ln \left(\frac{S_{0}}{K}\right)+\left(r+\frac{\sigma^{2}}{2}\right) T}{\sigma \sqrt{T}} \quad d_{2}=\frac{\ln \left(\frac{S_{0}}{K}\right)+\left(r-\frac{\sigma^{2}}{2}\right) T}{\sigma \sqrt{T}}=d_{1}-\sigma \sqrt{T}
$$

Let's suppose an investor decided to use spread of options in 06/17/2017 and stock price was tending to decrease at this point. 
Figure 12. Stock price of APU JSC /2017.06, MNT/

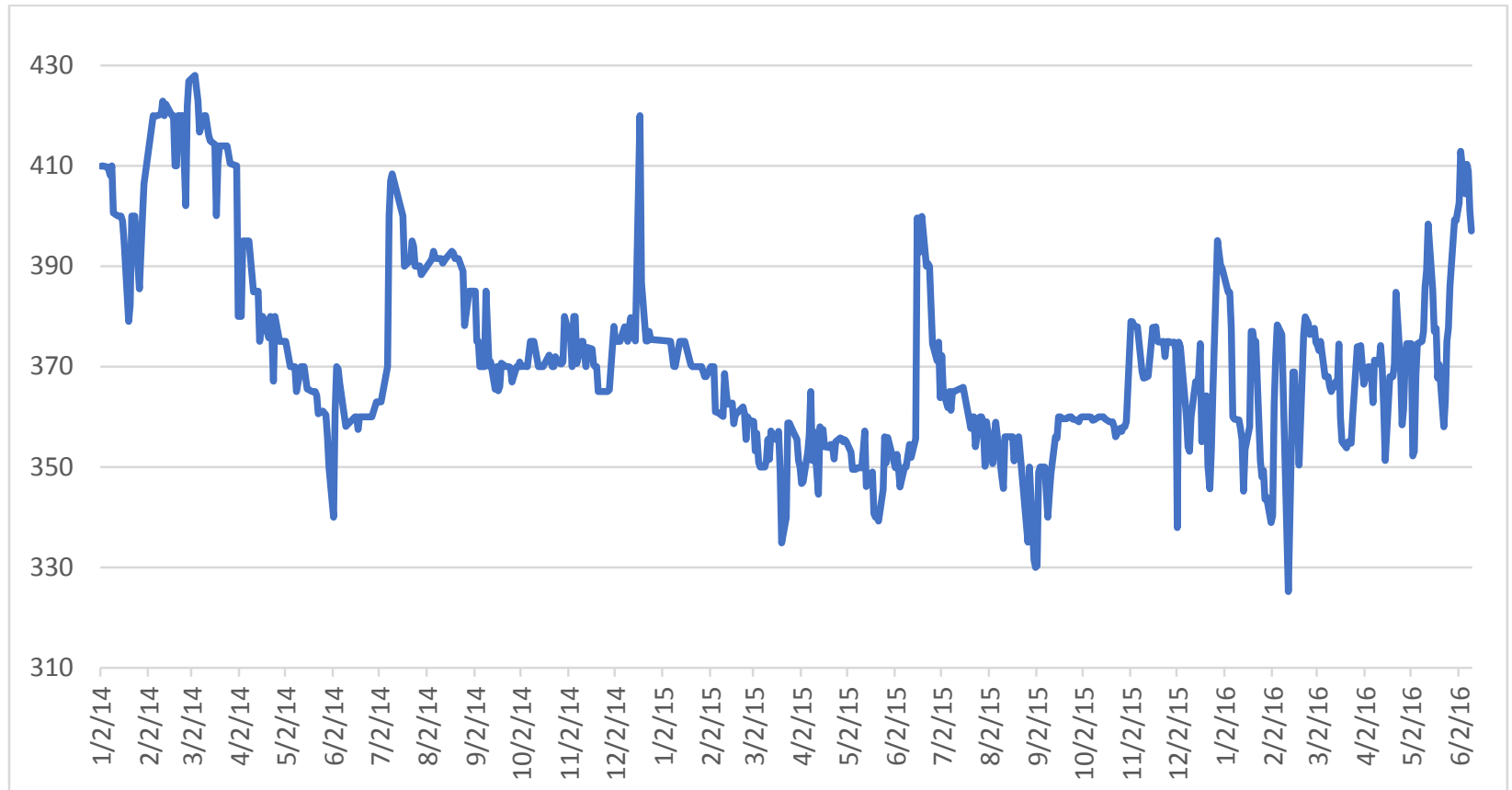

Assume that the investor thought that the stock price will rise, in which case the bull strategy has chosen a strategy. The reason for this choice is based on the monthly impact study of the TOP-20 companies analyzed above, and the share price of APU is expected to increase at the end of the year. Therefore, in June 2016, the bull strategy will be implemented on the shares as follows.

- $\quad$ Buy a 3-month call option and sell the call option at a price slightly higher than the bargain price to make bull spread.

If the share price was MNT 300 as of July 4 2017, the following calculation would be made.

- APU JSC's standard division of price return is $2.38 \%$

- $\quad$ So $=300 \mathrm{MNT}$

- $\mathrm{T}=90$ days

- $\quad \mathrm{R}-$ Risk free rate (Policy rate of Mongolian central bank) ${ }^{7}$

$\mathrm{C}=S_{0} N\left(d_{1}\right)-\mathrm{K} e^{-r T} N\left(d_{2}\right)$

$$
d_{1}=\frac{\ln \left(\frac{S_{0}}{K}\right)+\left(r+\frac{\sigma^{2}}{2}\right) T}{\sigma \sqrt{T}} \quad d_{2}=\frac{\ln \left(\frac{S_{0}}{K}\right)+\left(r-\frac{\sigma^{2}}{2}\right) T}{\sigma \sqrt{T}}=d_{1}-\sigma \sqrt{T}
$$

- $\mathrm{K} 1=400$

- $\mathrm{K} 2=410$

- We can see the result which P1 $=14.04, \mathrm{P} 2=14.39$ and if investors buy call option 1 at P1 price and sell call option 2 at P2 price, they can make profit which is 0.35 MNT.

\footnotetext{
${ }^{7}$ The reason why we chose policy rate as a risk-free rate is that there is no actively traded T-bill or Government bonds in Mongolia.
} 
On the other hand, the agreement is mutually beneficial and has the potential to overcome financial crisis (In the next part we will discuss how to overcome financial crisis).

\section{KHUH GAN JSC}

The company's shares have been traded since August 2008 and the chart below shows the volatility from the start of trading to September 2011. The company's shares will be used in the future based on the analysis and forecasting of future values. To make the analysis more realistic, we will work on data from the 2008 financial crisis situation and realistically measure the benefits of using a set of traditional market strategies.

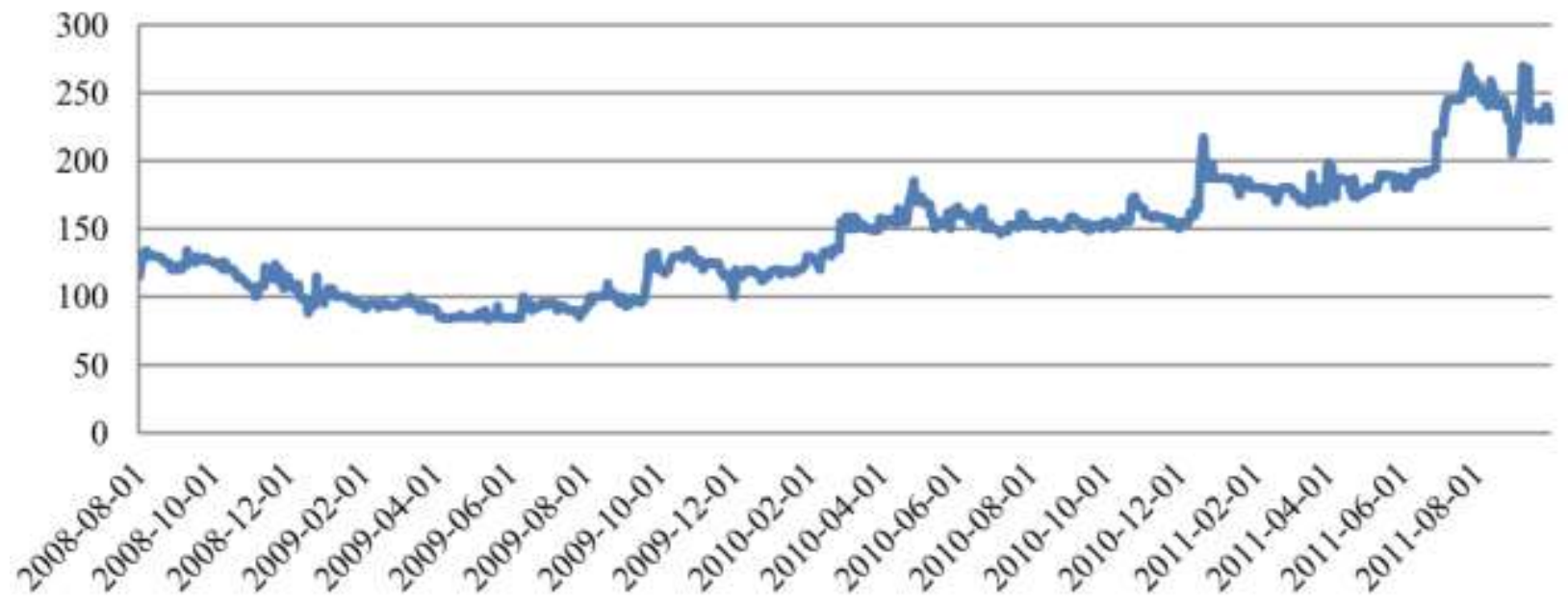

Figure 13. Stock performance of Khuh gan JSC /MNT/

According to the stock statistics, the highest share price is 270 , the lowest share price is 83 and the average share price is 143. Let's analyze this stock indicator and determine the future transaction strategy. To do this, it is necessary to perform an econometric analysis of the stock over time and predict the future value of the price. ARCH, AR and MA modeling will be used for analysis. When analyzing the exchange rate equation, the current exchange rate is influenced by the previous values of the 1st and 6th generation, which are modeled as AR (1), AR (6), MA (1), and MA (6). 
Table 1. Time series analysis of khuh Gan JSC

Dependent Variable: HGN

Method: Least Squares

MA Backcast: 16

\begin{tabular}{|c|c|c|c|c|}
\hline Variable & Coefficient & Std. Error & t-Statistic & Prob. \\
\hline $\operatorname{AR}(1)$ & 0.944601 & 0.020825 & 45.36004 & 0.0000 \\
\hline $\operatorname{AR}(6)$ & 0.056440 & 0.020931 & 2.696411 & 0.0072 \\
\hline $\mathrm{MA}(1)$ & -0.090055 & 0.040842 & -2.204968 & 0.0277 \\
\hline $\mathrm{MA}(6)$ & -0.113774 & 0.035530 & -3.202172 & 0.0014 \\
\hline R-squared & 0.987560 & \multicolumn{2}{|c|}{ Mean dependent var } & 143.2030 \\
\hline Adjusted R-squared & 0.987514 & \multicolumn{2}{|c|}{ S.D. dependent var } & 43.34987 \\
\hline S.E. of regression & 4.843914 & \multicolumn{2}{|c|}{ Akaike info criterion } & 5.998231 \\
\hline Sum squared resid & 18981.97 & \multicolumn{2}{|c|}{ Schwarz criterion } & 6.021359 \\
\hline Log likelihood & -2434.281 & \multirow{2}{*}{\multicolumn{2}{|c|}{ Hannan-Quinn criter. }} & 6.007109 \\
\hline Durbin-Watson stat & 2.002183 & & & \\
\hline \multirow[t]{3}{*}{ Inverted AR Roots } & 1.00 & $.44-.42 i$ & \multirow[t]{2}{*}{$.44+.42 i$} & \multirow[t]{2}{*}{$-.21+.50 \mathrm{i}$} \\
\hline & $-.21-.50 i$ & -.52 & & \\
\hline & \multicolumn{3}{|c|}{ Estimated AR process is nonstationary } & \\
\hline \multirow[t]{2}{*}{ Inverted MA Roots } & .71 & $.36-.60 i$ & \multirow[t]{2}{*}{$.36+.60 i$} & \multirow[t]{2}{*}{$-.33-.60 i$} \\
\hline & $-.33+.60 i$ & -.68 & & \\
\hline
\end{tabular}

We can see that R-squared is 0.987560 . It means $98.75 \%$ of the dependent variables can be explained by independent variables. And Durbin-Watson stat should be close to 2. According to the table, all variables are statically significant. 


$$
\begin{aligned}
& d_{1}=\frac{\ln \left(\frac{230}{263.9}\right)+\left(0.0029+\frac{0.047^{2}}{2}\right) 63}{0.047 \sqrt{63}}=0.3057 \\
& d_{2}=0.3057-0.047 \sqrt{63}=-0.0725 \\
& \mathrm{~N}(0.3057)=\text { normsdist }(0.3057)=0.62 \\
& \mathrm{~N}(-0.07259)=\text { normsdist }(-0.07259)=0.47 \\
& \mathrm{C} 1=230 * N(0,3057)-263.9 e^{-0,0029 * 63} N\left(-0,0725_{2}\right)=38.95 \\
& \mathrm{C} 2=K e^{-r T} N\left(-d_{2}\right)-S_{0} N\left(-d_{1}\right)=38.83426
\end{aligned}
$$

Figure 14. Actual and explained values

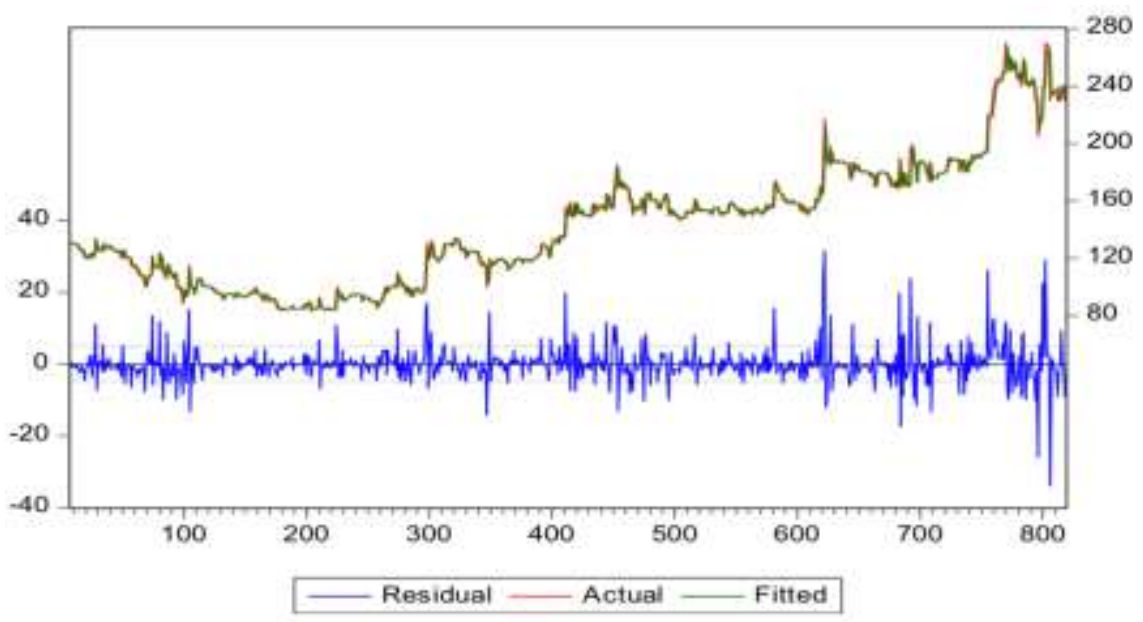

Figure 15. Calculation of call options on HGN

Once a suitable model has been selected and the price volatility has been assessed, it will be possible to predict the value of the stock after 3 months based on this model and determine the option strategy based on it.

Table 1. Calculation of call options

\begin{tabular}{|l|l|c|c|}
\hline & & Call (buy) & Call (sell) \\
\hline S & Current price & 230 & 230 \\
\hline K & Strike price & 263.9 & 264.2 \\
\hline T & Time to maturity & 63 & 63 \\
\hline R & Risk free rate & 0.0029 & 0.0029 \\
\hline SD & Standard division of return & 0.047665 & 0.047665 \\
\hline
\end{tabular}

\begin{tabular}{|c|c|r|}
\hline & Call (buy) & \multicolumn{1}{c|}{ Call (sell) } \\
\hline $\mathrm{d} 1$ & 0.305741 & 0.302738 \\
\hline $\mathrm{d} 2$ & -0.07259 & -0.07559 \\
\hline $\mathrm{N}(\mathrm{d} 1)$ & 0.620099 & 0.618955 \\
\hline $\mathrm{N}(\mathrm{d} 2)$ & 0.471067 & 0.469873 \\
\hline Price & 38.95196 & 38.83426 \\
\hline
\end{tabular}


The forecast value of the exchange rate after 63 working days or 3 months is 264.2 . Since the value of the exchange rate forecast is modeled with an upward trend, we will follow bull strategies when assuming that the exchange rate will rise. In other words, investors will buy a low-priced call option on HGN's shares and buy a more expensive call option. According to the Black Scholes model, the price of the options is as follows. Summarizing the calculations:

Let's take a look and combine calculations and strategies that we made. Assuming that the exchange rate rises, we follow all the spread strategies and get 2 call options with the same period with different exercise prices, and the following results are obtained.

Table 2. Sum of calculation

\begin{tabular}{|c|c|c|c|c|}
\hline After 3 months & $\begin{array}{c}\text { Whether exercise } \\
\text { contract or not }\end{array}$ & $\begin{array}{c}\text { Profit on stock } \\
\text { /MNT/ }\end{array}$ & $\begin{array}{c}\text { Profit on } \\
\text { contract/MNT/ }\end{array}$ & $\begin{array}{c}\text { Total profit } \\
\text { /MNT/ }\end{array}$ \\
\hline $\begin{array}{c}\text { Higher than } \\
\text { exercise price }\end{array}$ & Exercise 2 contracts & $264,2-263.9=0.3$ & $38.83-38.95=-0.11$ & 0.19 \\
\hline $\begin{array}{c}\text { Between exercise } \\
\text { prices }\end{array}$ & $\begin{array}{c}\text { Only exercise call } \\
\text { option which bought }\end{array}$ & $\begin{array}{c}\text { Depend on price. } \\
\text { Get profit until 0.3 }\end{array}$ & -0.11 & $\begin{array}{c}\text { Depend on } \\
\text { price }\end{array}$ \\
\hline $\begin{array}{c}\text { Lower than } \\
\text { exercise price }\end{array}$ & $\begin{array}{c}\text { Not exercise 2 } \\
\text { contracts }\end{array}$ & 0 & -0.11 & -0.11 \\
\hline
\end{tabular}

\section{CONCLUSION}

The capital market makes a real contribution to a country's economic and financial growth and development. The following conclusions are made in the framework of the research.

- Some countries with economies in transition, which started a few years ago, have achieved great success in a short time period with the successful achievement of stock markets. The trading of derivative market instruments has played a significant role in this success.

- Financial market crises occur in financial cycles and during this time financial market participants can overcome the downturn by entering into agreements with each other and sharing risks on both sides.

- Mongolia's stock market has a monthly impact, and stock prices are expected to fall early of the year. Due to the high volatility of Mongolian stock price, it is better to use the derivative market portfolio strategy.

- It was possible to make a profit of MNT 0.3 per share of a company (selected) by choosing a derivative market portfolio strategy against the sharp fall in stock prices and implementing the bull strategy identified in the analysis.

- The analysis of Khukh Gan JSC's share price shows that bull strategies can be followed, and this strategy is more likely beneficial in volatile market conditions.

- The main factor for the development of Mongolian stock market is the introduction of derivative instruments. To this end, it is important to introduce over-the-counter market, which is the most common form on the world stock market. For example, it will be base for gaining trading experience in derivative market instruments.

- In order to activate the stock exchange, it is necessary to attract more investors from foreign and domestic markets. For this reason, MSE needs to implement sophisticated hedging tools to make the market more stable and reliable.

\section{REFERENCES}

1. Jonh.C. Hull, (2002), Options Futures and Other Derivatives,

2. Jonh.C. Hull, (2008), Options Futures and Other Derivatives, 7th edition

3. Jorion. P, (2003), Financial Risk Manager handbook, John Wiley \& Sons, Inc, p243-257

4. Hardy. M, (2003), Modeling and Risk Management for Equity-Linked Life Insurance, John Wiley \& Sons, Inc., p157173

5. Ollson. C, Risk (2002), Management in Emerging, Markets Pearson Education print, p209-257

6. Ying Chen,Wolfgang Hdrdle, Vladimir Spokoiny, (2005), Portfolio Value at Risk Based on Independent Components Analysis

7. Alper Ozuna, Atilla Cifterb, Sait Yilmazer,(2007), Filtered Extreme Value Theory for Value-At-Risk Estimation 
8. Glyn A. Holton, (2002),History of Value-at-Risk: 1922-1998

Evis Kellezi, Manfred Gilli, (2000), Extreme Value Theory for Tail-Related Risk Measures Andrey Rogachev, (2002),

Dynamic Value-at-Risk

9. Dai Bo, (2001), Value at Risk

10. T. W. Yee, (2006), Family Functions for Extreme Value Data

11. Martin Odening, Jan Hinrichs, Using Extreme Value Theory to Estimate Value-at-Risk

12. Yong Bao, Aman Ullah, (2003), Bias of Value-at-Risk Model

13. Chris Brook, Gita Persand, (2000), Value at risk Market Crashes

14. C. Brooks, A. D. Clare, J.W. Dalle Molle and G. Persand, (2003), A Comparison of Extreme Value Theory Approaches for Determining Value at Risk

15. Demirguc-Kunt 6a Levine (1996),Sing (1997), Zervos (1998), Derivative markets in developing country 